\title{
Assessment of strategic development potential of the production units of enterprises of railway transport
}

\author{
Irina Tokmakova ${ }^{1 *}$, Natalia Panchenko ${ }^{2}$, Hanna Obruch $^{1}$, Anastasia Kozlova ${ }^{3}$, Hanna \\ Zaiets $^{1}$ \\ ${ }^{1}$ Ukrainian State University of Railway Transport, Department of Economics and Management of \\ Industrial and Commercial Business, 61050 Feerbach Square 7, Kharkov, Ukraine \\ ${ }^{2}$ Ukrainian State University of Railway Transport, Department of Higher Mathematics, 61050 \\ Feerbach Square 7, Kharkov, Ukraine \\ ${ }^{3}$ O.M. Beketov National University of Urban Economy in Kharkiv, Department of Tourism and \\ Hotel Management, Kharkov, Ukraine
}

\begin{abstract}
The article reveals the theoretical and methodological basis of the resource approach to the development of the strategic potential of railway enterprises, which is recognized as progressive in matters of the formation of competitive advantages at the present stage of management. The component structure of the strategic potential of enterprises has been clarified and the reasonability of diagnosing the strategic potential of railway enterprises within the framework of a competitive approach in such areas as unique resources and basic competences, operational competencies, adaptive competencies, "proactive competencies", and the ability to create common values has been explained. A method of assessing the level of development of the strategic potential of the production units of the branches of Ukrzaliznytsya JSC has been developed.
\end{abstract}

\section{Introduction}

The processes of globalization, European integration and liberalization form new conditions for managing the Ukrainian railway industry, in which survival and further effective development, urgent improvement of the main parameters of its activities and positions before competitors should be ensured. However, the strategic thinking of the management of JSC "Ukrzaliznytsia" is still limited to the assets that the company owns today, so its innovation and investment activities are aimed at solving many of the current problems that have accumulated over the past three decades. At the same time, the features of post-industrial society form new approaches to ensuring competitiveness, based on knowledge and competences. The speed at which railway enterprises are able to create the necessary assets and develop them, demonstrating a high level of adaptability to a changing external environment is really important. This nature of development highlights the strategic potential of the production units of the branches of Ukrzaliznytsya JSC as the basis for the

\footnotetext{
* Corresponding author: it.tokm@,ukr.net
} 
formation of long-term competitiveness of railway transport.

\section{Analysis of literature data and problem statement.}

The methodological basis for assessing the strategic potential of business entities is formed in the works by J. Barney, B. Wernerfelt, G. Hamel and K. Prahalad, D. Tisa, G. Pisano and E. Shuen, R. Nelson, S. Winter [1- 5] and others. Researchers point out that the assessment of the strategic potential of enterprises is an extremely difficult problem, especially in terms of choosing the methodological basis for the analysis, since the theory of strategic potential is a new direction that has not yet fully formed. Its foundations are laid in the resource concept of strategic management, according to which the source of long-term competitive advantages is the resource base of the enterprise, as well as the process of effective management, creation and combinations of resources. According to the generally accepted logic of the resource approach, enterprises form competences, influence resources and transform them into a new state. The unique resources and organizational abilities (competencies and/or dynamic abilities) form the strategic potential, which is the source of sustainable competitive advantages realized in the form of economic rents that are inaccessible to rivals.

Although in the field of railway transport, the assessment and formation of the strategic potential is not given due attention, certain aspects of the problem are revealed in the works by V.L. Dikan [6], in particular, in the development of such researchers as M.V. Koren [7], V. Hoop [8], V. Ovchinnikov [9], I. Tokmakova [10] and others. However, the existing differences in approaches to assessing the strategic potential of enterprises and absence of a scientifically recognized solution in this area in rail transport require further study of this problem.

\section{Substantiation of the approach to determining the components of the assessment of the strategic potential of the production units of railway enterprises}

The management of the strategic potential of the production units of railway enterprises, and in particular the assessment, requires the determination of its component structure. The generalization of the views of scientists on this issue [11-23] indicates the predominant use of two main approaches to the formation of the strategic potential architecture, namely, the functional and the competitive ones.

The functional structuring of the traditional potential is based on the allocated functional subsystems of the enterprise and their components. With this approach, the component model of the aggregate strategic potential of enterprises is determined by the structure of the production system and local potentials of various functional orientations. The differences in this arrangement are due to different views on grouping of areas of activity, factors and resources. A significant disadvantage of this direction in research is the identification of the components of the economic and strategic potential.

The generalized functional structure of the strategic potential can be represented by three levels of formation of its local potentials: production and technological; organizational and managerial; financial and economic. In general, the functional approach is focused on determining the rational structure of the strategic potential of the enterprise and evaluates its level on the basis of progressive regulatory ratios set by the most advanced technologies of individual enterprise subsystems. Its disadvantages are due to focusing on the limiting possibilities of resources, the minimum necessary for the existence of an enterprise on the market and its ability to compete in the external environment. 
Management of the strategic potential in this situation for enterprises will be reduced to supporting this minimum level and tracking the dynamics of the internal and external environment, which may affect the required minimum level.

At the same time, the management of strategic opportunities that enable the enterprise to become a leader determines the competitiveness of an enterprise. The source of competition is the combination of the necessary resources and competencies, which will ensure the implementation of the strategy and a reasonable choice of strategic alternatives in conditions of uncertainty, while maintaining the intra-balanced sustainable development of the enterprise. Thus, a competitive approach reveals the structure of strategic potential based on the identification of sources of ensuring competitive stability. The views on the structure of the strategic potential within the framework of this approach are systematized, supported by the scientific community, presented in the work of V.V. Vasilyeva [21], which defines such sources of competitiveness of strategic potential as resources and key competencies, where resources are tangible and intangible assets of an organization, and competences are a superstructure over resources, represent activities and processes by which an organization uses these resources. An example of the concretization of the above provisions is given by I.P. Otenko and A.S. Danevich [22] who define such components of the strategic potential of an industrial enterprise as: managerial competence, flexibility of the organizational structure, strategic position of the enterprise and its ability to ensure production and technological efficiency. In our opinion, A.D. Antonov [23] gives the most reasonable provisions containing a structured detailed description of key sources of enterprise competitiveness in the conditions of a post-industrial economy, which indicates the need to diagnose such elements of strategic potential: unique resources and basic competences; operational competences; adaptive competencies; "proactive competences"; ability to create shared values. The relevance of this list of components of competitiveness conditioned by the fact that it contains the factors that have a transformative effect on the fundamental characteristics of the behavior of enterprises in the post-industrial conditions of the development of society.

\section{Development of a methodology for assessing the strategic potential for the development of production units of railway enterprises}

The presented component structure of the strategic potential of the production units of railway transport enterprises and the advantages of using the expert method determines the approach and assessment methodology (Fig. 1).

The main assessment steps are as follows:

- formation of a system of particular indicators of strategic potential, taking into account the specifics of the production units of the branches of Ukrzaliznytsya JSC;

- determination of reference values of indicators by their rationing;

- standardization of indicators;

- determination of coefficients of significance of indicators; calculation of the integral indicator;

- interpretation of the results.

Taking into account the proposals on the components of the strategic potential of enterprises, the main indicating factor characterizing their condition at the level of production units of railway transport enterprises include:

1. Unique resources and core competencies:

1.1 The proportion of the active part of fixed assets, taking into account the age structure;

1.2 The proportion of qualified personnel; 
1.3 Coefficient of validity of the active part of fixed assets;

1.4 Utilization of production capacity;

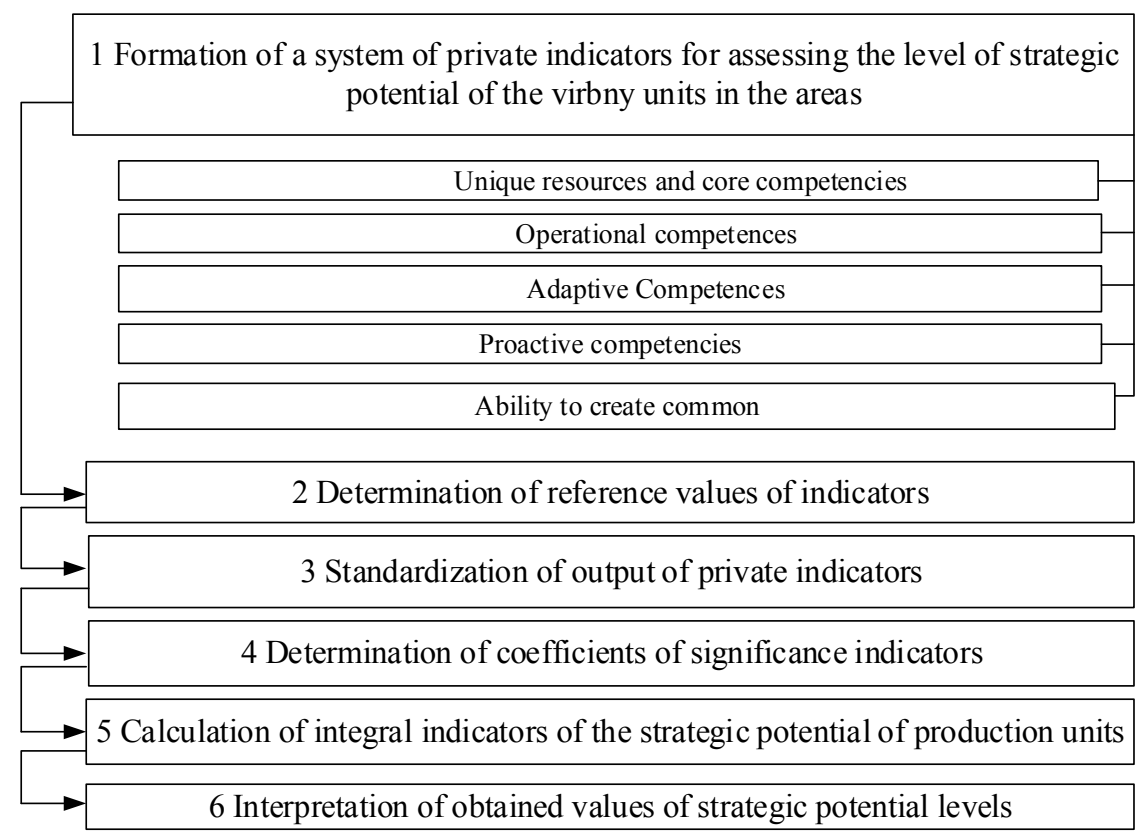

Fig.1. The scheme of calculation of the integral indicator of the strategic potential of the production units of enterprises of railway transport.

2. Operational competencies:

2.1 Indicators of resource efficiency;

2.2 Indicators of quality and reliability;

3. Adaptive competencies:

3.1 Share of investments in innovations in the total amount of expenses;

3.2 Proportion of universal fixed assets;

3.3 Level of progressiveness of production and management technologies;

4. "Proactive competencies":

4.1 Proportion of workers who have improved their skills;

4.2 Proportion of proactive management personnel;

4.3 Coefficient of renewal of fixed assets;

4.4 Proportion of workers rationalizers;

5. Ability to create shared values:

5.1 Proportion of investments in the improvement of personnel and their living conditions;

5.2 Share of expenditures for charity,

5.3 Proportion of positive communication channels.

In order to carry out standardization of indicators of strategic potential, it is important to determine the ideal value, perhaps based on the rationing of indicators by applying expert assessments.

To assess the level of strategic potential, its characteristics such as critical, low, satisfactory, medium and high are offered. Although the assessment range is from 0 to 1 , such intervals for assessing the level of development of strategic potential can be determined: critical level is from 0 to 0.2 ; low - from 0.21 to 0.4 ; satisfactory - from 0.41 to 0.6 ; medium - from 0.61 to 0.8 ; high - from 0.81 to 1 .

Evaluation of the strategic potential of an enterprise with the help of the proposed 
methodology allows finding weak elements in its structure and making an appropriate strategic decision aimed at ensuring the competitive stability of railway transport.

\section{Conclusion.}

For the effective implementation of strategic decisions to ensure the sustainability of the functioning and development of the production units of railway transport in the long term, in unstable environmental conditions, it is necessary to identify areas and corresponding measures to increase the level of strategic potential. After all, the availability and quality of resources, competencies and abilities substantially determines and individualizes the configuration of possible vectors of the strategic development of enterprises.

The key stage of management of the strategic potential of the production units of the branches of Ukrzaliznytsia JSC determined the assessment of its condition, requires the identification of components and the development of methodological bases for their assessment. In the process of disclosing the main approaches to the structuring of strategic potential, the priority is given to the study of the state of sources of competitive advantage, taking into account the features of the external conditions of their functioning. The proposed system of indicators of strategic potential characterizes the ability of domestic rail transport to ensure its competitiveness in the long term. It has been substantiated that the obtained results of the assessment of the level of strategic potential allow us to identify promising reserves and develop effective measures to ensure the development of the production units of the branches of Ukrzaliznytsia JSC in accordance with the railway industry development strategy.

\section{References}

1. J. Barney. Journal of Management, 17 (1), 99-120 (2009)

2. B. Wernerfelt. Strategical Management, 5.2, 171-180 (1984)

3. C. K. Prahalad, G.Hamel. Harvard Business Review, 68.3, 79-91 (1990)

4. R. R.Nelson, I.S.J. Winter, Evolutionary Theory of Economic Change. Per. from English M., Delo, 536 (2002)

5. D.J. Teece, G.Pisano, A.Shuen. Strategic Management Journal, 18, 509-533 (1997).

6. V. L. Dikan, M. V. Koren. Collection of scientific papers of the Ukrainian State University of Railway Transport, 154, 98-103 (2015)

7. M. V. Root. Ensuring innovative development of railway transport based on the formation of an industrial and logistic system. Kharkiv, 21 (2013)

8. G. V. Hoop Ensuring the development of the potential of competitiveness of car-building enterprises of Ukraine. Kharkiv, 265 (2017)

9. V. A. Ovchinnikova. Strategic management of the development of railway transport in Ukraine: monograph. M.: USURT, 427 (2017)

10. I. V. Tokmakova Ensuring the harmonious development of railway transport in Ukraine: monograph. M.: USURT, 403 (2015)

11. V.I. Bitsa. Vestnik Khmelnytsky National University, 6.2, 203 - 206 (2011)

12. T. N. Kibuk. Strategic potential of an enterprise (on the example of enterprises in the metallurgical industry of Ukraine). Kyiv, 20 (2010)

13. V.D. Markova. Strategic management: a course of lectures. M.: INFRA-M; Novosibirsk: Siberian Agreement, 288 (1999)

14. G. B. Kleiner, V. L. Tambovtsev, R. M. Kachalov. Enterprises in an unstable economic environment: risks, strategy, safety. Moscow: Economy, 425 (1997)

15. V.N. Gavva, Estimation of Enterprise and Industry Potential: A Monograph. Kharkov. 
Aviation. Institute", 287 (2004)

16. O. A. Sushchenko. Formation of the strategic potential of the enterprise. Lugansk, 20 (2002)

17. S. B. Alekseev. European vector of economic development, 2 (15), 17-25 (2013)

18. M.I. Kovach. Bulletin of NLTU of Ukraine, 23. (10), 207-212 (2013)

19. Yu. V. Samoilik. Technological audit and production reserves, 2 (2), 32-35 (2011)

20. Ye.V. Lagunova. Problems of Management, 6, 40-44 (2007)

21. V. V. Vasilyeva Management of strategic potential of the organization. Moscow, 26 (2010)

22. I. P.Otenko, A. S. Danevich. Business Inform, 9, 302-307 (2014)

23. A. D. Antonov. Economy and Entrepreneurship, 3 (26), 139-148 (2012) 